\title{
Brasil e Timor-Leste: reflexões sobre formação de professores universitários e cooperação educacional
}

\author{
Raquel Antunes Scartezini* \\ Manuel Belo de Carvalho
}

\section{Resumo}

A cooperação educacional estabelecida entre Brasil e Timor-Leste se pauta no princípio da horizontalidade e prevê a atuação conjunta com vistas à redução das desigualdades sociais. Este princípio também pressupõe que as ações estabelecidas no âmbito da colaboração internacional sejam de caráter transitório, enfocando a solução de problemas específicos que demandam atuação conjunta. No âmbito do apoio ao Ensino Superior, as ações do Programa de Qualificação Docente e Ensino de Língua Portuguesa (PQLP) estão inseridas, principalmente, no contexto da Universidade Nacional Timor Lorosa'e (UNTL) em atividades de ensino, pesquisa e extensão. No caso específico das atividades de ensino, pressupõe-se que as aulas sejam ministradas em codocência de forma a contribuir para a formação do atual quadro docente, tanto o brasileiro quanto o timorense. Este artigo visa refletir sobre as atividades da cooperação educacional brasileira desenvolvidas no Ensino Superior em TimorLeste, indagando se estas têm contribuído para a formação e o aperfeiçoamento de docentes universitários de ambos os países. Sendo assim, apresenta-se uma breve revisão teórica sobre a importância da formação pedagógica do professor do Ensino Superior, muitas vezes relegada a segundo plano nas Instituições de Ensino Superior tanto do Brasil quanto de Timor-Leste. Posteriormente, destaca-se as potencialidades das atividades de codocência na formação do professor universitário de ambos os países. Finalmente, conclui-se que os resultados dessa cooperação bilateral horizontal são bastante expressivos e que a codocência contribui para a formação pedagógica dos professores de ambos países. Além disso, observam-se ganhos na aprendizagem da língua portuguesa pelos professores e estudantes timorenses.

Palavras-chave: Ensino Superior. Formação de Professores. Cooperação Educacional.

\footnotetext{
* Doutora em Educação pela Universidade de Brasília (UnB). Articuladora Geral do Programa de Qualificação de Docentes e Ensino de Língua Portuguesa no Timor-Leste (PQLP), da Coordenação de Aperfeiçoamento de Pessoal de Nível Superior (CAPES).
} 


\section{Introdução}

A cooperação educacional estabelecida entre Brasil e Timor-Leste teve seu início em 2002, logo após a restauração da independência do país asiático, ainda sob o governo provisório das Nações Unidas. Desde então, vem se construindo uma relação bilateral que se pauta no princípio da horizontalidade e prevê a atuação conjunta com vistas à redução das desigualdades sociais.

A cooperação horizontal refere-se à cooperação entre países em desenvolvimento que tenta cooperar de forma desinteressada, sem impor interesses comerciais. Este princípio também pressupõe que as ações estabelecidas no âmbito da colaboração internacional sejam de caráter transitório e que enfoquem a solução de problemas específicos que demandam atuação conjunta.

De acordo com os preceitos assumidos pela política externa brasileira (BRASIL, 2010), a cooperação técnica internacional visa superar as assimetrias, promover o crescimento econômico sustentável, propiciar a melhoria da qualidade de vida das populações favorecidas, bem como fortalecer as instituições dos países parceiros, favorecendo a geração de conhecimentos técnicos e a capacitação de recursos humanos.

$\mathrm{Na}$ área da educação em Timor-Leste a cooperação técnica tem como missão apoiar a decisão constitucional desse país (TIMOR-LESTE, 2002) de estabelecer como seus idiomas oficiais a Língua Portuguesa e o tétum, bem como contribuir para o cumprimento da Lei de Bases da Educação (TIMOR-LESTE, 2008), que define esses mesmos idiomas como línguas do sistema educativo, realidade ainda não alcançada em Timor-Leste.

O Memorando de Entendimento (BRASIL, 2002a) firmado entre os dois países ainda em 2001 antevia que as ações no âmbito da cooperação educacional bilateral teriam como objetivos "o fortalecimento da cooperação educacional e interuniversitária, a formação e o aperfeiçoamento de docentes e pesquisadores, e o intercâmbio de informações e experiências no âmbito educacional". A subsequente criação do Programa de Qualificação de Docentes e Ensino de Língua Portuguesa no Timor-Leste (PQLP), sob coordenação acadêmica da Universidade Federal de Santa Catarina (BRASIL, 2002b, 2004), e seu respectivo ajuste complementar (BRASIL, 2011), colocam por objeto que o programa se assente em três áreas fundamentais, a saber: formação inicial e continuada dos docentes, fomento ao ensino da língua portuguesa e apoio ao Ensino Superior.

No âmbito do apoio ao Ensino Superior - o qual priorizaremos neste artigo -, as ações do PQLP estão inseridas, principalmente, no contexto da Universidade Nacional Timor Lorosa'e (UNTL) em 
atividades de ensino, pesquisa e extensão. Todas essas atividades, alinhadas aos princípios da horizontalidade e da atuação conjunta, devem ser realizadas de forma integrada aos parceiros timorenses. No caso específico das atividades de ensino, pressupõe-se que as aulas sejam ministradas em codocência, de forma a contribuir para a formação do atual quadro docente, brasileiro e timorense. Esse é um campo privilegiado no qual a cooperação internacional para a educação entre Brasil e TimorLeste pode contribuir para o desenvolvimento dos professores do Ensino Superior de ambos os países.

De acordo com o Plano Nacional Estratégico de Educação 2011-2030, “the overall quality of Higher Education is low and not co-ordinated to meet the development needs of Timor-Leste. The Ministry aims to develop Higher Education system which can provide services according to internationally recognised quality standards" (TIMOR-LESTE, 2011, p. 33). O referido plano estratégico alinha-se à Declaração de Bolonha de 1999 (BOLOGNA PROCESS, 1999) e estabelece metas para atingir padrões e descrições internacionais para as qualificações do Ensino Superior ${ }^{2}$.

Dentre as metas estabelecidas visando cumprir os padrões internacionais de qualidade, o Ministério destaca a necessidade de que as Instituições de Ensino Superior (IES) sejam formadas por professores qualificados e, para tanto, estabelece como ações: projetar e implementar programas de desenvolvimento profissional em serviço para todos aqueles professores de instituições de Ensino Superior e desenvolver um sistema para monitorar a qualidade do ensino nesse âmbito ${ }^{3}$.

O conjunto das instituições timorenses de Ensino Superior tem, então, como desafio promover programas de formação docente "através da coordenação de parcerias com reconhecidas instituições internacionais, promovendo, por exemplo a integração de docentes internacionais nos quadros docentes das instituições" (TIMOR-LESTE, 2012, p. 23). No entanto, de acordo com o diagnóstico elaborado pelo Ministério da Educação, a comunicação entre os parceiros de desenvolvimento e o Ministério é ineficaz e inexiste um alinhamento entre a cooperação internacional e as necessidades e prioridades do setor da educação (TIMOR-LESTE, 2011).

Visando atender a essas demandas, o Ministério da Educação de Timor-Leste reconhece a competência docente como um conjunto de características, conhecimentos e habilidades que os professores devem apresentar nos níveis pedagógico, social e profissional. "A competência do docente é determinante para a qualidade e para a implementação dos três pilares do ensino superior: 1) docência/pedagogia; 2) investigação; e 3) serviço à comunidade” (TIMOR-LESTE, 2014, p. 2). Este mesmo documento apresenta um Manual de Certificação do Docente Universitário (CEDU), cujo pressuposto exige do docente a melhoria contínua de sua atividade profissional. Em contrapartida, as 
IES “são obrigadas a fornecer condições aos docentes que possibilitem a melhoria de suas competências profissionais" (TIMOR-LESTE, 2014, p. 4).

É nesse contexto que o presente artigo visa refletir sobre as atividades da cooperação educacional brasileira desenvolvidas no Ensino Superior em Timor-Leste, indagando se estas têm contribuído para a formação e o aperfeiçoamento de docentes universitários de ambos os países. O nosso ponto de partida é a nossa própria experiência enquanto atores neste processo, já que nosso envolvimento é grande com essa temática: a primeira autora deste artigo, além de exercer a função de gestora do PQLP em Timor-Leste, atua como professora visitante na Faculdade de Educação, Artes e Humanidades (FEAH/UNTL); o segundo autor é professor titular dessa mesma instituição, exerce as funções de docente e gestor na FEAH/UNTL.

As reflexões que aqui se constroem são fruto de diálogo e articulações travadas no exercício conjunto de nossas funções no âmbito da FEAH/UNTL. A cada semestre procuramos identificar as necessidades de atuação da cooperação brasileira no âmbito do ensino. Os chefes de departamento elaboram listas de disciplinas indicando quais necessitam de apoio da cooperação brasileira. Em reuniões internas do PQLP são avaliadas as disponibilidades dos cooperantes para atender tais demandas. Normalmente, seleciona-se um professor brasileiro e um professor timorense para ministrar conjuntamente cada disciplina (o que chamamos de "codocência"), porém, ainda há casos em que o professor brasileiro assume sozinho a docência da turma em virtude da indisponibilidade de professores timorenses para tanto. Logo, acompanhamos os trabalhos dos professores brasileiros e timorenses envolvidos nas atividades de ensino durante todo o semestre letivo.

Em nossos constantes encontros de trabalho foi identificada a proficuidade de debatermos o tema "cooperação educacional e formação de professores universitários" e avaliarmos as atividades de codocência que são estabelecidas em tal contexto. Essa situação de codocência, alinhada ao princípio da horizontalidade, é considerada ideal no campo da cooperação educacional em atividades de ensino. No entanto, nem sempre tem sido possível garantir a atuação conjunta de um professor estrangeiro juntamente com um timorense por diferentes razões, de que trataremos posteriormente.

De início, apresentamos um breve estudo bibliográfico sobre o tema "docência universitária" a fim de indicar a importância da formação pedagógica do professor do Ensino Superior, muitas vezes relegada a segundo plano nas IES tanto do Brasil quanto de Timor-Leste. Em seguida, trazemos as nossas percepções e dos cooperantes brasileiros sobre como têm sido realizadas as atividades de 
cooperação educacional na dimensão do ensino na UNTL. Por fim, refletimos sobre as potencialidades das atividades de codocência na formação do professor universitário de ambos os países.

\section{A docência universitária}

Recentemente, a aula universitária surgiu como um objeto de estudo crescente no âmbito da investigação acadêmica no Brasil (ANASTASIOU, 2003a, 2003b, 2006; BOLZAN; ISAIA, 2008; BRZEZINSKI, 2001; CORDEIRO, 2007; CUNHA, 2007, 2010a, 2010b; ISAIA; BOLZAN, 2009; MELLO; ALMEIDA FILHO; RIBEIRO, 2009; PACHANE, 2009; PIMENTA; ANASTASIOU, 2010), embora ainda não constitua uma área sólida de produção (MOROSINI, 2000). Seguindo uma tendência global, esta recente atenção ao ensino ocorre em resposta às novas demandas que se impõem à universidade e, mais especificamente, pelo fato de a aula ser um "espaço" central para a concretização das reformas curriculares pelas quais vêm passando os cursos universitários (TARDIF; LESSARD, 2005).

Diversos autores denunciam a pouca preocupação com a questão da formação pedagógica de professores do Ensino Superior brasileiro, apontando a inexistência de processos formativos para a docência neste nível de ensino (ANASTASIOU, 2006; BOLZAN; ISAIA, 2008; CUNHA, 2007, 2010b; PACHANE, 2009). A formação dos estudantes de pós-graduação fixa-se no processo de pesquisa e, em grande parte dos casos, distancia-se de qualquer abordagem pedagógica. Tal estado de coisas conduz o exercício da docência superior como um habitus ${ }^{4}$, ou seja, quando o professor ministra uma aula totalmente despreparado do ponto de vista pedagógico e reproduz as formas pelas quais foi formado, repetindo a ação de seus antigos professores ${ }^{5}$ (ANASTASIOU, 2006; CUNHA, 2010a).

A combinação de todos esses fatos leva os pesquisadores da docência universitária a afirmar a importância da formação pedagógica continuada dos profissionais que exercem a função docente nas universidades. Distintas propostas são abordadas, sempre enfatizando a importância do ensino relacionado à pesquisa, de forma a promover o pensamento crítico e a capacidade de escuta e observação, propiciando o diálogo e a adoção de uma postura ética. Ensinar e aprender contemplando a tríplice dimensão universitária exige o envolvimento do sujeito, sendo um desafio que se compõe de um percurso de inúmeras possibilidades na direção de uma formação humana integral (CORDEIRO, 2007). 
Para tanto, é essencial o exercício de compreensão do paradigma hegemônico de ensino, sobre o qual se sustentam as propostas pedagógicas docentes (de reprodução do conhecimento cientificamente acumulado ou do conhecimento como processo de produção). Isso porque, para a referida proposta de indissociabilidade entre ensino, pesquisa e extensão, faz-se necessária uma mudança paradigmática sobre ensinar e aprender a partir de um novo estatuto científico-social (CUNHA, 2007).

Embora a docência universitária venha despertando o interesse no âmbito acadêmico, a produção nessa área ainda é escassa. Uma das possíveis razões se encontra no fato de que não há um consenso a respeito do que caracteriza um bom professor universitário, o que, necessariamente, passa pela concepção da docência em si mesma (MONEREO; WEISE; ÁLVAREZ, 2013). A docência universitária é resultado da confluência de fatores tanto pessoais quanto circunstanciais.

Como caracteres pessoais, pode-se considerar a própria formação do docente, sua atitude perante os alunos, sua disciplina curricular e a instituição. Igualmente essenciais para o êxito dos professores universitários no exercício de suas funções são a formação no objeto do seu ensino (formação na área e disciplina a lecionar e formação para a investigação) e a sua preparação para o exercício da função docente, isto é, sua formação psicossociopedagógica (CANO GONZÁLES; REVUELTA GUERRERO, 1999). Já os fatores circunstanciais são aqueles provenientes da rotina acadêmica e da realidade social e política.

As ações dos professores estão, portanto, amparadas pelas dimensões subjetiva, cultural e histórica, as quais extrapolam os conhecimentos científicos. A docência possui um arcabouço de saberes peculiares. Refletir sobre tais saberes, tentando reconhecê-los e compreender como afetam a dimensão pedagógica e incidem na estruturação profissional docente, é condição sine qua non para pensar os programas de formação inicial e continuada de professores (CUNHA, 2010a).

Nesse encaminhamento, o processo de se construir continuamente como professor envolve a compreensão do processo coletivo que inclui o outro (estudantes e colegas de departamento, por exemplo) como parceiro essencial à reflexão, uma vez que o processo identitário se constrói pelo intercâmbio de representações acerca dos significados da profissão, assim como do significado que cada professor atribui à atividade docente em seu cotidiano. 


\section{As atividades de cooperação educacional e a codocência no Ensino Superior}

Conforme exposto anteriormente, nosso material empírico de análise neste artigo possui duas frentes: percepções de um professor timorense e de cooperantes brasileiros que atuam no PQLP. Na primeira parte, trazemos um diálogo estabelecido entre os autores, no qual o segundo autor expôs suas expectativas e percepções sobre as cooperações educacionais estabelecidas em Timor-Leste com distintos países.

Na segunda parte, trazemos a análise de um documento de 2014, em que os cooperantes brasileiros estavam empenhados em definir diretrizes comuns para a atividade docente em TimorLeste. Nesse ano, foram realizados intensos debates acerca dos seus campos de atuação, tendo sido a codocência um tema amplamente discutido. Os resultados de tais discussões foram transformados em um documento: o Projeto Político Pedagógico (PPP) do Programa de Qualificação Docente e Ensino de Língua Portuguesa (PQLP) em Timor-Leste.

\section{A percepção do professor timorense}

O professor em questão tem reconhecida experiência em Timor-Leste na área de educação e formação de professores. É formado pela UNTL e cursou o Mestrado em Educação pela Universidade do Minho, em Portugal. É professor do Departamento de Formação de Professores do Ensino Básico da Faculdade de Educação, Artes e Humanidades da UNTL. Até 2014, exerceu a função de diretor de departamento do curso de Formação de Professores do Ensino Básico. A partir de 2015, assumiu a função de vice-decano da FEAH/UNTL.

A Universidade Nacional Timor Lorosa'e, única universidade pública de Timor-Leste, foi criada em 2000 e:

[...] compreende as seguintes unidades orgânicas de ensino e investigação identificadas por ordem cronológica: a) Faculdade de Agricultura; b) Faculdade de Engenharia, Ciências e Tecnologia; c) Faculdade de Educação, Artes e Humanidades; d) Faculdade de Medicina e Ciências da Saúde; e) Faculdade de Economia e Gestão; f) Faculdade de Direito; g) Faculdade de Ciências Sociais. (TIMOR-LESTE, 2010).

O Departamento de Formação de Professores do Ensino Básico foi criado em 2005 pelos exprofessores formadores de docentes do Ensino da Língua e Literatura Indonésia, da Faculdade de Formação de Professores e Ciências de Educação (Fakultas Keguruan dan Ilmu Pendidikan - FKIP) da 
antiga Universidade Timor-Leste, Universitas Timor-Timur (UNTIM), no período da invasão Indonésia com o apoio de alguns professores da cooperação brasileira e da missão portuguesa (UNTL, 2014).

$\mathrm{Na}$ atualidade, entre os principais desafios que a universidade enfrenta, destaca-se promover a melhoria contínua de seu quadro docente e, ao mesmo tempo, manter em seus departamentos um número suficiente de professores que possa garantir a oferta de todas as disciplinas previstas nos currículos de seus cursos. O investimento na formação de seus professores acontece, prioritariamente, através da participação de docentes em cursos de pós-graduação stricto-sensu em universidades estrangeiras. Esse fato impacta no segundo desafio mencionado anteriormente, já que, com isso, o número de professores nos departamentos reduz-se. É nesse contexto que as atividades da cooperação educacional estão inseridas.

O professor timorense explicita a sua representação de cooperação:

Quando se fala em "cooperação", subentende-se uma ação conjunta entre duas partes. No caso da cooperação educacional entre Brasil e Timor-Leste, supõe-se que os professores brasileiros e timorenses atuarão em atividades de educação de forma colaborativa. Um exemplo concreto na UNTL são as atividades de codocência que supõe dois professores trabalhando conjuntamente uma mesma disciplina desde o planejamento das aulas até a regência e avaliação das mesmas. (Relato inédito colhido em diálogo entre os coautores do texto).

Para o professor, os docentes devem vivenciar uma nova experiência a partir da codocência, seja ela uma "nova didática", uma nova visão, um novo conhecimento sobre a sua área de especialidade. O professor brasileiro ganha uma nova experiência de ensinar em um país novo com uma diferente cultura e, com isso, enriquece seu domínio acerca do processo ensino-aprendizagem. O timorense ganha a experiência de aprender o português com os brasileiros e tem uma nova experiência de ensino: como elaborar um plano de aula com escolhas de métodos, técnicas e estratégias distintas daquelas que usualmente utiliza, uma maneira diferente de conduzir uma aula, explicar uma matéria e até mesmo novos modelos de avaliação.

A visão do professor remete-nos à dialogicidade freireana prevista em toda situação de ensino (FREIRE, 1985). Para um diálogo efetivo é indispensável considerar a alteridade, o que implica reconhecimento e valorização do outro. O outro é, simultaneamente, similar a e diferente de mim, o que cria o desafio de respeitá-lo em sua singularidade. Portanto, em uma situação de docência compartilhada não se trata de realizar a transferência de saber daquele que sabe mais para o outro 
desprovido de qualquer saber significativo. Tratam-se de dois sujeitos que, a partir de seus conhecimentos, construirão algo totalmente novo no trabalho colaborativo.

Mas o que tem acontecido em Timor-Leste ao longo desses anos? Há muito tempo se efetua a cooperação educacional em atividades de ensino, mas cada um trabalha com a sua ação. Cada um efetua o seu trabalho com o seu próprio planejamento, utilizando unicamente o seu conhecimento. Desde as primeiras cooperações instituídas em Timor-Leste, tem sido classificado como "atividade de cooperação em educação" qualquer pessoa que viesse trabalhar em Timor-Leste, mas, na verdade, a cooperação propriamente dita não configura deixar o profissional que vem de um país estrangeiro trabalhar sozinho para que os timorenses sintam o resultado de sua ação a posteriori. Isto não é uma cooperação! (Relato inédito colhido em diálogo entre os coautores do texto).

Segundo o relato do professor, os serviços de cooperação no sistema educativo timorense nem sempre atingem o resultado esperado porque tanto os brasileiros quanto os portugueses que trabalham em Timor-Leste, sejam professores, assessores ou instrutores, trabalham sozinhos. Na perspectiva do professor, nenhum dos timorenses os acompanha para que possam adquirir novas experiências e, em um determinado momento, encaminhar sozinho o processo de desenvolvimento do sistema educativo timorense. De tal forma, em sua opinião, ao longo desses 14 anos, os timorenses continuam a observar sem participar.

Especificamente no que diz respeito à docência na FEAH/UNTL, problematizamos a percepção do professor e tentamos analisar o que leva os professores timorenses e brasileiros, por vezes, a não trabalhar em parceria. Muitas vezes o departamento não possui professores para ministrar as disciplinas e os professores estrangeiros assumem a docência das mesmas, uma vez que, em alguns casos, os alunos estão pendentes destas disciplinas para poderem se graduarem. Portanto, é justamente com o apoio dos programas de cooperação internacional que a Faculdade pode, alternativamente, manter em seus departamentos um número suficiente de professores, enquanto seus profissionais aprimoram sua formação em cursos de pós-graduação no exterior e, de tal forma, garantir a oferta de todas as disciplinas previstas nos currículos de seus cursos.

Há ainda situações em que um professor timorense é nomeado como codocente do professor brasileiro, acontecem alguns encontros prévios para entrega da ementa da disciplina e repasse de algumas informações administrativas básicas e, então, é dito ao professor brasileiro para sentir-se à vontade para ministrar a disciplina como achar melhor. Os professores voltam a se encontrar somente no final do semestre. E ainda há casos em que essa nomeação acontece apenas formalmente, os professores nunca chegam a travar contato. Nesses casos é comum que o professor timorense nomeado 
esteja exercendo alguma outra função pública, embora permaneça no quadro da universidade. Nos casos em que a atividade conjunta de professores estrangeiros e timorenses é prevista, seria útil compreender as reais causas pela qual esta não acontece e identificar as possibilidades de garantir a parceria de trabalho.

O professor gestor enfatiza que a universidade necessita da cooperação internacional com países da Comunidade dos Países de Língua Portuguesa (CPLP) por dois principais motivos. Em primeiro lugar, para auxiliar no desenvolvimento da própria língua portuguesa. Na sua opinião, a codocência favorece o uso do português em sala de aula, promovendo o aprendizado da língua tanto pelos professores quanto pelos estudantes. É notório, também, pela experiência dos professores brasileiros que ministram aulas para alunos em um determinado semestre e, alguns semestres mais tarde, observar que esses mesmos estudantes, em virtude de terem tido aulas com distintos professores lusófonos, desenvolvem a proficiência na língua. Nessa situação, se o professor timorense não fluente na língua portuguesa participar ativamente das aulas durante todo o semestre letivo, certamente também terá chances de evoluir no domínio e fluência do português e cumprir as legislações nacionais.

A cooperação na área educacional ainda é necessária para contribuir com a formação pedagógica dos professores nos diferentes níveis de ensino. Nas palavras do professor:

[...] para mudar completamente a didática tradicional dos professores timorenses. Isto porque, hoje em dia, a maioria dos professores timorenses escreve no quadro e lê o texto como sendo uma explicação. Já quando o professor timorense trabalha com docentes de outras nacionalidades, aprende novas metodologias, utiliza outras referências bibliográficas distintas das habituais, pode conhecer várias estratégias e técnicas para que o aluno compreenda o conteúdo de uma forma mais fácil e por via da utilização dos materiais didáticos e tecnológicos. (Relato inédito colhido em diálogo entre os coautores do texto).

A observação do professor está alinhada aos planos do Ministério da Educação de Timor-Leste (TIMOR-LESTE, 2012) que tanto destacam a necessidade de formação continuada dos professores do Ensino Superior (TIMOR-LESTE, 2011) quanto sugerem a integração de docentes internacionais em seus quadros como forma de contribuir para o desenvolvimento de seu quadro permanente. O professor menciona casos de parcerias bem estabelecidas no âmbito da FEAH em que a codocência e a prática dialógica acontecem, contribuindo para o aprendizado da língua portuguesa, além de ricas experiências de ensino e aprendizagem. 


\section{A percepção dos cooperantes brasileiros}

As percepções dos cooperantes brasileiros são levantadas a partir do PPP do PQLP, documento este concebido por 70 professores que atuaram em Timor-Leste entre os anos de 2013 a 2014.

A elaboração do PPP teve como principal objetivo estabelecer diretrizes comuns para a atuação desses profissionais em Timor-Leste. O documento, concebido democraticamente por meio de reuniões de trabalho, leituras, diálogos e debates, apresenta um registro da história de Timor-Leste e uma breve revisão do conceito de cooperação internacional e história da cooperação educacional entre Brasil e Timor-Leste. O texto também apresenta referenciais teóricos e metodológicos consoantes com a missão e objetivos do PQLP. Por fim, são delineadas informações sobre a gestão e avaliação do programa.

O tema da codocência comparece em uma seção específica do PPP (BRASIL, 2015) que se destina a apresentar diretrizes aos professores brasileiros que vêm trabalhar em Timor-Leste. O documento apresenta esse processo como uma dinâmica de ensino e aprendizagem centrada na colaboração entre dois ou mais professores.

A codocência, em princípio, consiste em um apoio ao professor titular na preparação da aula, ampliação de bibliografia com títulos em língua portuguesa ou no aprimoramento da ementa das disciplinas dos diversos cursos (chamado de sílabo nas universidades de Timor-Leste). (BRASIL, 2015, p. 30; grifo nosso).

Inicialmente os professores demonstram uma visão assimétrica entre os profissionais envolvidos na atividade de codocência. A palavra "apoio" revela uma concepção de cooperação que provavelmente ainda se faz presente nas representações de alguns cooperantes brasileiros. Pode ser compreendida como uma ideia de cooperação como "ajuda", uma ação "assistencialista" e "benevolente" incompatíveis com a atual visão de cooperação exposta no próprio PPP que, alinhada ao escopo dos Organismos Intergovernamentais e Internacionais (OII), é atualmente concebida como "[...] esforço conjunto e uma forma compensatória pelos impactos da colonização e descolonização" (BRASIL, 2015, p. 22).

A mesma concepção pode ser identificada, logo em seguida, em outro excerto do mesmo documento, no qual é afirmado que os cooperantes brasileiros poderão resolver os impasses encontrados no processo de ensino compartido. Essa ideia sugere que os professores brasileiros são aqueles que detêm o saber e que poderão suprir as necessidades dos professores timorenses desprovidos deste: "Ao trabalhar de forma colaborativa, os cooperantes podem sanar as dificuldades dos 
envolvidos no processo, atendendo melhor àqueles que possuem necessidades de um atendimento particularizado ou com mais atenção" (BRASIL, 2015, p. 30; grifo nosso).

No excerto seguinte, o documento expõe uma interpretação horizontal da atividade, pressupondo que o exercício da docência aconteça de forma compartilhada.

No entanto, a codocência não se restringe ao fato de dois professores assumirem a regência da turma, mas também engloba a preparação, planejamento e escolha dos métodos e dinâmicas adequados para o uso em sala de aula. Dessa forma, há um trabalho de cooperação, em que os envolvidos contribuem com suas habilidades e conhecimentos no processo de crescimento mútuo. (BRASIL, 2015, p. 31).

O texto ainda revela que a codocência é um tema que traz dúvidas aos cooperantes brasileiros que trabalham nas instituições de Ensino Superior timorenses. Isso se deve ao fato de que o que acontece cotidianamente nas atividades de codocência entre um professor brasileiro e um professor timorense não coincide com aquilo que era esperado pelos cooperantes, conforme exposto no documento elaborado pelos mesmos:

[...] existem diversas situações que fazem com que a codocência se confunda com a docência e o professor da cooperação brasileira assuma a disciplina quase integralmente. Essas situações relacionam-se com a falta de professores timorenses para atuar em sala de aula ou com o fato de os professores não terem conhecimento do tema e ministrarem a aula com referências em línguas não oficiais como indonésio e inglês. (BRASIL, 2015, p. 30).

No trecho vemos que as questões colocadas pelo professor timorense se coadunam com o que dizem os brasileiros, que bem explicam alguns dos motivos por tal situação.

O documento ainda se pauta em literatura sobre o tema e expõe seis diferentes situações de codocência: aquela em que um ensina e o outro observa; aquela em que um ensina e o outro auxilia; a docência paralela; aquela em que são preparadas diferentes estações de ensino na sala de aula; a docência alternada entre os dois professores; e, por fim, a possibilidade de que os dois professores trabalhem juntos. Finalmente, o documento apresenta outras duas possibilidades de codocência:

a. Todos os professores participando de todos os processos - 1) codocência no planejamento e na regência da turma. Nessa modalidade, os professores se encontram extraclasse, fazem o planejamento e ambos assumem a regência mutuamente, colocando em prática o que foi previamente planejado; 2) os professores planejam juntos, mas ministram as aulas em momentos diferentes, por exemplo, cada conteúdo ou dia será de responsabilidade de um dos professores;

b. os professores participam de parte do processo - 1) a codocência pode acontecer mesmo na divisão de tarefas, por exemplo com um professor ou um grupo de 
professores no planejamento e outro professor ou grupo na execução (regência das aulas) ou planejamento de atividades e correção das mesmas. Dessa forma, os envolvidos necessitam de um grau de organização e interação maior, tendo em vista que não haverá um elemento que participará de todo o processo. (BRASIL, 2015, p. 32).

Por fim, os professores consideram que todas as decisões acerca do processo de ensino devem envolver ambos os docentes e ressaltam que essa pode ser uma rica experiência não apenas para os profissionais envolvidos, mas também para os alunos. Estas são consideradas como situações ideais para as atividades de codocência. No entanto, diante da distinta realidade encontrada nas salas de aulas, os professores que não têm o seu parceiro de trabalho acabam por ministrar as aulas sozinhos e, muitas vezes, verbalizam que se sentem fazendo o que é possível mediante as circunstâncias.

\section{Encontros e desencontros}

Ao analisar as percepções do professor timorense e dos cooperantes brasileiros, é possível observar que apresentam uma mesma visão do que seria uma situação ideal de docência compartilhada. Ambos ainda ressaltam que a codocência favorece a troca de experiências entre os professores de ambas as nacionalidades.

O professor timorense enfatiza a importância dessas atividades para o aprendizado da língua portuguesa por alunos e professores de seu país. Contudo, em algumas ocasiões, as atividades de codocência estabelecidas no âmbito do Ensino Superior não condizem com as expectativas de nenhum deles. Observa-se que aspectos administrativos, tais como falta de professores permanentes nos departamentos, professores licenciados para participar de formação em pós-graduação e excesso de trabalho dos professores atuantes nos departamentos, por exemplo, acabam por fazer com que a codocência seja prejudicada e aconteça em um grau menor do que o esperado.

Do ponto de vista administrativo da universidade, opta-se por resolver os problemas mais imediatos, como conseguir professores para garantir a oferta da grade curricular aos alunos, em detrimento de favorecer o desenvolvimento profissional docente, ignorando, assim, as potencialidades da atividade de codocência na formação dos professores universitários. Com isso, as atividades da cooperação correm o risco de adotar um caráter assistencialista, visto que provê uma falta imediata em detrimento de contribuir para o desenvolvimento dos recursos humanos dos países envolvidos.

Ainda são observados casos em que o professor timorense se omite da parceria e deixa a preparação e a condução da disciplina exclusivamente nas mãos do professor brasileiro, que, por sua 
vez, aceita essa situação e, em alguns casos, sente-se até mesmo "livre" para ministrar aulas "à sua maneira”. Também há casos vivenciados pelos cooperantes brasileiros em que o professor timorense comparece à sala de aula apenas para assistir às aulas do professor brasileiro.

Os autores debateram sobre os motivos que levam o professor timorense a preferir não ministrar as aulas juntamente com o professor brasileiro e chegaram à conclusão de que podem ser vários: falta de tempo em virtude de sobrecarga de trabalho; pouco domínio da língua portuguesa e constrangimento em ter que ministrar aulas com um falante nativo; sentir-se intimidado e adotar uma postura defensiva, já que pressupõe que o professor brasileiro é aquele que vem para impor suas verdades. Enfim, podemos supor, mas não sabemos o que leva a esse ocasional distanciamento. Talvez esse seja um campo de estudo a ser explorado no futuro.

Quando o professor timorense afirma a necessidade de "mudar completamente a didática tradicional dos professores timorenses", nos permite duas interpretações diversas. Primeiro, que há uma suposição de que todos aqueles professores brasileiros que se deslocam para Timor-Leste têm maiores e melhores conhecimentos que os professores timorenses. Apesar do fato de os editais de seleção de bolsistas brasileiros estarem sendo aprimorados para encontrar profissionais com perfil mais adequado à cooperação educacional em solo timorense (CASSIANI; LINSINGEN; PEREIRA, 2016), não se pode tomar por definitivo que todos os professores brasileiros tenham "melhor didática".

Em segundo lugar, "mudar completamente" sugere ignorar por completo os conhecimentos construídos pelos professores timorenses ao longo de suas carreiras na docência. Mais uma vez, o professor timorense coloca os professores “internacionais" no lugar de detentores do "verdadeiro saber", uma vez que, supostamente, há mais tempo, têm contato e são formados pelas potências do norte. Aqui, pode-se observar o risco de, mais uma vez, exercermos a "colonialidade do saber"6, pois diante de um apelo desses o profissional brasileiro pode se sentir seduzido a atender à demanda de suprir as "deficiências do colega timorense".

Cabe ressaltar ainda, que muitos dos professores brasileiros que participam da cooperação educacional em Timor-Leste são jovens professores com uma excelente formação acadêmica em seu objeto de ensino, mas que ainda se encontram no início de suas carreiras no Ensino Superior. A experiência na docência dos professores timorenses é essencial para contribuir para suas atuações em sala de aula e formações enquanto docentes nesse nível de ensino (formação psicossociopedagógica). Há aqueles cooperantes que verbalizam se sentirem mais seguros quando o professor timorense está presente. Seja pelo domínio da língua tétum (muitas vezes necessária para clarificar alguma explicação 
em sala de aula), seja pelo conhecimento do funcionamento da universidade, ou mesmo pelo domínio do funcionamento do processo de ensino-aprendizado no país, como um dado de sua cultura (fatores circunstanciais). Portanto, a atividade de estágio docente em Timor-Leste para professores brasileiros representa uma oportunidade efetiva de formação para a docência no Ensino Superior.

Por outro lado, a formação do corpo docente timorense nas áreas e disciplinas curriculares, nas dinâmicas psicossociopedagógicas e no domínio da língua portuguesa são frequentemente destacadas como resultados efetivos das atividades de cooperação educacional entre os dois países. Reconhece-se, portanto, que estas podem ser potencializadas nas atividades de atuação conjunta, fortalecendo as possibilidades de intercâmbio de informações e experiências e, assim, de formação continuada.

\section{Considerações Finais}

A última missão do Programa de Qualificação Docente e Ensino de Língua Portuguesa (BRASIL, 2013), somente no âmbito da Universidade Nacional Timor Lorosa'e, realizou mais de sete mil atendimentos entre atividades de ensino, pesquisa e extensão. Tratando especificamente do domínio do ensino, envolvendo atividades de docência e codocência, mais de cinco mil e oitocentos estudantes tiveram aulas com professores brasileiros enviados a Timor-Leste nos últimos dois anos. Além dessas atividades, esses professores realizaram orientações a mais de cinquenta estudantes em seus trabalhos de final de curso; participaram das bancas de defesa destes trabalhos; apoiaram a pós-graduação na organização de três eventos acadêmicos; e, como resultado de todo esse processo de parceria, produziu sete livros destinados a contribuir com o desenvolvimento acadêmico e científico de ambos os países. O PQLP, portanto, enquanto um instrumento da política externa brasileira, tem cumprido a sua missão de contribuir para o fortalecimento institucional da única universidade pública timorense.

Nesse momento, Brasil e Timor-Leste trabalham conjuntamente no delineamento de uma nova proposta de cooperação educacional. Como forma de contribuir com o planejamento de propostas futuras, nosso objetivo neste artigo foi avaliar se as ações do PQLP têm contribuído para a formação e o aperfeiçoamento dos professores universitários de ambos os países. O material empírico utilizado nesta análise foram as percepções de um professor timorense, gestor da Faculdade de Educação, Artes e Humanidades da UNTL e de 70 cooperantes brasileiros que atuaram no PQLP.

A importância da formação pedagógica dos professores do Ensino Superior é destacada na fala do professor e gestor timorense, que reitera a necessidade de que os professores aprendam a planejar 
aulas, utilizar diferentes estratégias e recursos didáticos, bem como aplicar diferentes formas de avaliação. Tanto em Timor-Leste quanto no Brasil, o acesso à carreira docente universitária exige, prioritariamente, investimentos no campo científico por meio da pós-graduação stricto sensu, deixando o campo pedagógico totalmente inexplorado (CUNHA, 2010a).

O professor timorense explicita casos de parcerias bem estabelecidas em que a codocência e a prática dialógica acontecem. Ele enfatiza que essa atividade favorece o uso da língua portuguesa em sala de aula, bem como contribui com a formação pedagógica dos professores envolvidos. Os cooperantes brasileiros, por sua vez, relatam que o exercício da docência compartilhada resulta em uma profícua experiência formativa para os docentes das duas nacionalidades.

Por outro lado, tanto o professor timorense quanto os cooperantes brasileiros expressam certo desapontamento pelo fato de nem sempre ser possível garantir o exercício conjunto da docência entre profissionais dos dois países. Efetivamente, o fato de os professores timorenses e brasileiros nem sempre trabalharem de forma integrada representa uma perda de oportunidade formativa para ambos. Esse deveria ser um foco de atenção na elaboração de futuros projetos de cooperação educacional entre as duas nações.

Vale relembrar que uma meta do Plano Nacional Estratégico de Educação 2011-2030 de TimorLeste (TIMOR-LESTE, 2011) é promover programas de desenvolvimento profissional em serviço. O PQLP é mantido pela CAPES, instituição brasileira responsável pelo aperfeiçoamento de professores de nível superior, e pressupõe, como contrapartida ao trabalho realizado em Timor-Leste, a formação do quadro de professores universitários brasileiros participantes.

Assim, para que se possa garantir a almejada e mutuamente valorosa relação de aprendizagem e desenvolvimento entre as duas nações lusófonas, é importante que as instituições envolvidas sejam capazes de avaliar as potencialidades da codocência enquanto instrumento formativo de professores universitários e encontrar soluções possíveis para que essa ação ocorra com maior frequência.

Já foi constatado que o exercício da docência em um ambiente colaborativo promove distintas oportunidades de aprendizagem, inclusive advindas de conflitos entre o par de professores. Resultados do estudo promovido por Dang (2013) com professores vietnamitas em formação sugerem que observar e dialogar sobre as situações vivenciadas conjuntamente em sala de aula favoreceram o desenvolvimento docente. O exercício da docência compartilhada pode constituir-se em uma valiosa estratégia de formação contínua de professores, uma vez que, por via do diálogo e de uma postura ética, ao dialogar com o outro a fim de preparar uma aula, observar a atuação do seu colega perante a turma, 
escutar sobre a sua própria atuação, favorece não apenas a formação pedagógica, mas também o desenvolvimento da identidade profissional docente.

A partir de uma perspectiva da teoria da atividade, Smagorinsky et al. (2004) também visualizam a formação da identidade do professor como um processo de negociação entre diferentes concepções de ensino. Assim, aprender a ensinar é, em parte, um processo de construção de uma identidade no meio de sistemas de relações. Existem vários sistemas de relações envolvidas na atividade docente, configurações muitas vezes conflitantes sobrepostas que fazem a formação da identidade bastante desafiadora (SMAGORINSKY et al., 2004).

No entanto, é preciso considerar que Timor-Leste é um país em vias de desenvolvimento e enfrenta a escassez de profissionais em seus quadros. Por esse motivo, entende-se que há momentos em que as cooperações devem exercer a função de suprir algumas necessidades imediatas da nova nação. Isso envolve ministrar disciplinas para as quais não existam professores, por exemplo. Entretanto, sempre que possível, é recomendável que não se perca de vista os objetivos estabelecidos no projeto de cooperação entre os dois países.

\section{Notas}

1 “A qualidade geral do Ensino Superior é baixa e não coordenada para atender às necessidades de desenvolvimento de Timor-Leste. O Ministério tem como objetivo desenvolver um sistema de Ensino Superior que possa fornecer serviços de acordo com padrões de qualidade internacionalmente reconhecidos" (TIMOR-LESTE, 2011, p. 33, tradução nossa).

${ }^{2}$ Os impactos do Processo de Bolonha e seu consequente alinhamento com as políticas públicas para a educação superior de países não europeus já haviam sido previstos no encontro de Londres (BOLOGNA PROCESS, 2007).

${ }^{3}$ O Processo de Bolonha, no documento referente à reunião de monitoramento de 2003, recomendou a avaliação dos programas e das instituições, incluindo avaliação interna, avaliação externa, participação dos estudantes e publicação de seus respectivos resultados (BOLOGNA PROCESS, 2003).

${ }^{4} \mathrm{Na}$ teoria de Bourdieu, habitus é "concebido como um sistema de esquemas individuais, socialmente constituído de disposições estruturadas (no social) e estruturantes (nas mentes), adquirido nas e pelas experiências práticas (em condições sociais específicas de existência), constantemente orientado para funções e ações do agir cotidiano" (SETTON, 2002, p. 63).

5 Há que se considerar que existem bons professores que "têm didática", como os próprios alunos reconhecem, independentemente de sua formação específica. Os docentes podem ter referências de bons professores a partir de sua própria história enquanto estudantes, e estes modelos, possivelmente, inspiram a sua prática. O que se enfatiza aqui é a influência do paradigma hegemônico da ciência moderna na forma de ensinar verdades prontas e acabadas. Professores que trilham caminhos fora deste paradigma ainda são exceção.

${ }^{6}$ A colonialidade do saber revela que "para além do legado de desigualdade e injustiças sociais profundos do colonialismo e imperialismo, já assinalados pela teoria da dependência e outras, há um legado epistemológico do eurocentrismo que nos impede de compreender o mundo a partir do próprio mundo em que vivemos e das epistemes que lhe são próprias" (PORTO-GONÇALVES, 2005, p. 3). Para aprofundar essa noção, consulte Lander (2005). 


\section{REFERÊNCIAS}

ANASTASIOU, Léa das Graças. Ensinar, aprender, apreender e processos de ensinagem. In: ANASTASIOU, Léa das Graças; ALVES, Leonir Passate. Processos de ensinagem na universidade. Joinville, SC: Univille, 2003a. p. 11-38.

ANASTASIOU, Léa das Graças. Da visão de ciência à organização curricular. In ANASTASIOU, Léa das Graças; ALVES, Leonir Passate. Processos de ensinagem na universidade. Joinville, SC: Univille, 2003b. p. 39-65.

ANASTASIOU, Léa das Graças. Docência na educação superior. In: RISTOFF, Dilvo; SEVEGNANI, Palmira. Docência na educação superior. Brasília, DF: Inep, 2006. p. 147-171.

BOLOGNA PROCESS. The Bologna Declaration of 19 June 1999: joint declaration of the European Ministers of Education. Bologna: European Higher Education Area, 1999. Disponível em: $<$ http://www.ond.vlaanderen.be/hogeronderwijs/bologna/documents/MDC/BOLOGNA_DECLARATI ON1.pdf>. Acesso em: 30 ago. 2015.

BOLOGNA PROCESS. Realising the European Higher Education Area: communique of the Conference of Ministers responsible for Higher Education in Berlin on 19 September 2003. Berlin: European Higher Education Area, 2013. Disponível em:

$<$ http://www.ond.vlaanderen.be/hogeronderwijs/bologna/documents/MDC/Berlin_Communique1.pdf>. Acesso em: 30 ago. 2015.

BOLOGNA PROCESS. London Communiqué Towards the European Higher Education Area: responding to challenges in a globalised world. London: European Higher Education Area, 2007. Disponível em:

<http://www.ond.vlaanderen.be/hogeronderwijs/bologna/documents/MDC/London_Communique18Ma y2007.pdf>. Acesso em: 30 ago. 2015.

BOLZAN, Doris P. V.; ISAIA, Silvia Maria de A. Pedagogia universitária e aprendizagem docente: tensões e novos sentidos da profissionalidade. In: SEMINARIO INTERNACIONAL DE LA RED ESTRADO, 7., 2008. Buenos Aires. Anais... Buenos Aires: Red Estrado, 2008.

BRASIL. Ministro dos Negócios Estrangeiros e Cooperação. Memorando de entendimento, na área de cooperação educacional, entre o Governo da República Federativa do Brasil e a Administração Transitória das Nações Unidas em Timor-Leste, de 24 de agosto de 2001. Diário Oficial da União, Brasília, DF, 30 jan. 2002a.

BRASIL. Decreto $n^{\circ} 4.319$, de 1 de agosto de 2002. Dispõe sobre o Programa de Qualificação Docente e Ensino de Língua Portuguesa no Timor-Leste. Diário Oficial da União, Brasília, DF, 2 ago. 2002 b.

BRASIL. Decreto n ${ }^{\circ} 5.274$, de 18 de novembro de 2004. Institui o Programa de Qualificação de Docente e Ensino de Língua Portuguesa no Timor-Leste, e dá outras providencias. Diário Oficial da União, Brasília, DF, 19 nov. 2004. 
BRASIL. Ministério das Relações Exteriores. Balanço de Governo 2003-2010. Brasília, DF: MRE, 2010. Disponível em: <http://www.balancodegoverno.presidencia.gov.br/sintese-politica/sintesepolitica-versao-impressa>. Acesso em: 14 ago. 2014.

BRASIL. Ministério da Educação. Ajuste complementar ao acordo de cooperação educacional entre o Governo da República Federativa do Brasil e o Governo da República Democrática de Timor-Leste para implementação do "Programa de Qualificação de Docentes e Ensino da Língua Portuguesa em Timor-Leste", de 2 de março de 2011. Diário Oficial da União, Brasília, DF, 23 maio 2011, 2011.

BRASIL. Coordenação de Aperfeiçoamento de Pessoal de Nível Superior. Programa de Qualificação de Docentes e Ensino de Língua Portuguesa no Timor-Leste. Edital nº 76/2013. Brasília, DF, 2013. Disponível em: <http://www.capes.gov.br/images/stories/download/editais/Edital-076-2013-TimorLeste-PQLP-31102013.pdf>. Acesso em: 30 ago. 2015.

BRASIL. Coordenação de Aperfeiçoamento de Pessoal de Nível Superior. Programa de Qualificação de Docentes e Ensino de Língua Portuguesa no Timor-Leste. Projeto Político Pedagógico. Brasília, DF: CAPES, 2015. Disponível em: <http://pqlp.pro.br/wp-content/uploads/2015/05/ProjetoPol\%C3\%ADtico-Pedagógico-PQLP.pdf>. Acesso em: 5 set. 2015.

BRZEZINSKI, Iria. Pós-Graduação em educação brasileira e a produção do conhecimento profissional: emergência de um novo paradigma para a formação de professores? In: BRZEZINSKI, Iria; TAVARES, José. Conhecimento profissional de professores: a práxis educacional como paradigma de construção. Fortaleza: Demócrito Rocha, 2001. p. 53-80.

CANO GONZÁLES, Rufino; REVUELTA GUERRERO, Clara. La formación permanente del profesorado universitario. Interuniversitaria de Formación del Profesorado, v. 2, n. 1, 1999. Disponível em: <http://www.aufop.com/aufop/uploaded_files/articulos/1224326368.pdf>. Acesso em: 30 ago. 2015.

CASSIANI, Suzani; LINSINGEN, Irlan von; PEREIRA, Patrícia Barbosa. (Pre)textos para pensar a cooperação educacional em Timor-Leste: algumas referências para o internacionalismo solidário. Perspectiva, Florianópolis, v. 34, n. 2, 2016. No prelo.

CORDEIRO, Telma de Santa Clara. A aula universitária, espaço de múltiplas relações, interações, influências e referências. In: CORDEIRO, Telma de Santa Clara. Reflexões e práticas em pedagogia universitária. São Paulo: Papirus, 2007. p. 111-124.

CUNHA, Maria Isabel da. Pesquisas e qualidade no ensino: aprendizagens e possibilidades na educação superior. In: ENGERS, Maria Emília A.; MOROSINI, Marília Costa. Pedagogia universitária e aprendizagem. Porto Alegre: EdiPUCRS, 2007. p. 31-38.

CUNHA, Maria Isabel da. A docência como ação complexa. In: CUNHA, Maria Isabel da. Trajetórias e lugares de formação da docência universitária: da perspectiva individual ao espaço institucional. São Paulo: Junqueira e Marin, 2010a. p. 19-34. 
CUNHA, Maria Isabel da. Diálogo com as experiências: que conclusões incitam os estudos?. In: CUNHA, Maria Isabel da. Trajetórias e lugares de formação da docência universitária: da perspectiva individual ao espaço institucional. São Paulo: Junqueira e Marin, 2010b. p. 291-305.

DANG, Thi Kim Anh. Identity in activity: Examining teacher professional identity formation in the paired-placement of student teachers. Teaching and Teacher Education, n. 30, p. 47-59, 2013.

FREIRE, Paulo. Extensão ou comunicação? Rio de Janeiro: Paz e Terra, 1985.

ISAIA, Silvia Maria de Aguiar; BOLZAN, Doris Pires Vargas. Trajetória da docência: articulando estudos sobre os processos formativos e a aprendizagem de ser professor. In: ISAIA, Silvia Maria de Aguiar; BOLZAN, Doris Pires Vargas. Pedagogia universitária e desenvolvimento profissional docente. Porto Alegre: EdiPUCRS, 2009. p. 121-44.

LANDER, Edgardp (Org.). A colonialidade do saber: eurocentrismo e ciências sociais. Buenos Aires: CLACSO, 2005. (Colección Sur Sur).

MELLO, Alex Fiúza de; ALMEIDA FILHO, Naomar de; RIBEIRO, Renato Janine. Por uma universidade socialmente relevante. Brasília, DF: Fórum Nacional de Educação Superior, 2009.

MONEREO, Carles; WEISE, Crista; ÁLVAREZ, Ibis. Cambiar la identidad docente en la universidad: Formación basada en incidentes dramatizados. Infancia y Aprendizaje, n. 36, p. 323-340, 2013.

MOROSINI, Marília Costa. Docência universitária e os desafios da realidade nacional. In: MOROSINI, Marília Costa(Org.). Professor do ensino superior: identidade, docência e formação. Brasília: INEP/MEC, 2000. p. 11-20.

PACHANE, Graziela. Formação de docentes frente a um mundo em transformação. In: ISAIA, Silvia Maria de Aguiar; BOLZAN, Doris Pires Vargas. Pedagogia universitária e desenvolvimento profissional docente. Porto Alegre: EdiPUCRS, 2009. p. 249-266.

PIMENTA, Selma Garrido; ANASTASIOU, Léa das Graças. Docência no ensino superior. 4. ed. São Paulo: Cortez, 2010.

PORTO-GONÇALES, Carlos Walter. Apresentação da edição em português. In: LANDER, Edgard (Org.). A colonialidade do saber: eurocentrismo e ciências sociais. Buenos Aires: CLACSO, 2005. (Colección Sur Sur). p. 3-5.

TIMOR-LESTE. Constituição da República Democrática de Timor-Leste. Díli, 20 maio 2002.

TIMOR-LESTE. Lei n ${ }^{\text {14, }} 29$ de outubro de 2008. Lei de Bases da Educação. Jornal da República: publicação oficial da República Democrática de Timor-Leste, Díli, 29 out. 2008.

TIMOR-LESTE. Decreto Lei no 16, de 20 de outubro de 2010. Estatuto da Universidade Nacional Timor Lorosa'e (UNTL). Jornal da República: publicação oficial da República Democrática de TimorLeste, Díli, 20 out. 2010. 
TIMOR-LESTE. Ministério da Educação. National Education Strategic Plan: 2011-2030. Díli, 2011.

TIMOR-LESTE. Ministério da Educação. Plano do Ministério da Educação:2013-2017. Díli, 2012.

TIMOR-LESTE. Ministério da Educação. Diploma Ministerial nº 33, de 10 de setembro 2014. Jornal da República: publicação oficial da República Democrática de Timor-Leste, Díli, 10 set. 2014.

SETTON, Maria da Graça. J. A teoria do habitus em Pierre Bourdieu: uma leitura contemporânea. Revista Brasileira de Educação, Rio de Janeiro, n. 20, p. 60-70, 2002.

SMAGORINSKY, Peter et al. Tensions in learning to teach: accommodation and the development of a teaching identity. Journal of Teacher Education, v. 55, n. 1, p.8-24, 2004.

TARDIF, Maurice; LESSARD, Claude O. O trabalho docente: elementos para uma teoria da docência como profissão de interações humanas. 2. ed. Petrópolis, RJ: Vozes, 2005.

UNTL. Universidade Nacional Timor Lorosa'e. Faculdade de Educação, Artes e Humanidades. Projeto Político Pedagógico do Curso de FPEB. Díli, UNTL, 2014. 


\section{Brazil and East Timor: Reflections on university teachers training and educational cooperation}

\begin{abstract}
The educational cooperation established between Brazil and Timor-Leste is guided by the principle of horizontal cooperation and foresees a concerted action with a view to reducing social inequalities. This principle also implies that the established actions within the scope of international collaboration are of a temporary nature, focusing on solving specific problems that require cooperative strategy. In support to Higher Education, especially at Universidade Nacional Timor Lorosa'e, the actions of the Teacher Training Program and Portuguese Language Teaching focus mainly on teaching, research and extension. In the specific case of teaching, it is presupposed that the classes are taught in a co-teaching environment in order to contribute to the formation of the current teaching staff, both Brazilian and Timorese. This article aims to reflect on the activities of the Brazilian educational cooperation developed in Higher Education in Timor-Leste inquiring whether they have contributed to the formation and improvement of academics from both countries. Thus, a brief literature review is presented to indicate the importance of pedagogical training of higher education teachers, which is often relegated into the background in HEIs in both Brazil and Timor-Leste. Later, the article highlights the potential of coteaching activities in the development of coordinated teaching skills for university teachers training. It concludes that the results of this bilateral horizontal cooperation are very significant and that co-teaching activities contributes to pedagogical training for teachers from both countries. Moreover, it is observed that, participating of this activities, Timorese teachers and students improve their knowledge about Portuguese language.
\end{abstract}

Keywords: Higher Education. Teacher training. Educational cooperation.

\section{Brasil y Timor- Oriental: Reflexiones sobre la formación de los profesores universitarios y la cooperación educativa}

\section{Resumen}

La cooperación educativa establecida entre Brasil y Timor-Leste se guía por el principio de horizontalidad y prevé una acción conjunta con el fin de reducir las desigualdades sociales. Este principio también implica que las acciones previstas en el marco de la colaboración internacional son de carácter temporal, centrándose en la solución de aquellos problemas específicos que requieran de una acción conjunta. En apoyo a la Educación Superior, concretamente en el contexto de la Universidad Nacional Timor Lorosa'e, las acciones del Programa de Formación del Profesorado y Enseñanza de la Lengua Portuguesa se realizan en relación a la docencia, la investigación y la extensión universitarias. En el caso específico de la enseñanza, se asume que las clases se imparten en situación de co-docencia con el fin de contribuir a la formación del profesorado actual, tanto brasileño como timorense. Este artículo tiene como objetivo reflexionar sobre las actividades de cooperación educativa brasileña desarrolladas en la Educación Superior de Timor-Leste, e indagar si estas contribuyen a la formación y al perfeccionamiento de académicos de ambos países. El artículo presenta una breve revisión de la literatura sobre la importancia de la formación pedagógica de los profesores de educación superior, a menudo relegada a un segundo plano en las IES en Brasil y en Timor-Leste. Posteriormente, subraya el potencial de las actividades de co-docencia en la formación del profesor universitario de ambos países. Finalmente, se concluye que los resultados de esta cooperación bilateral horizontal son muy significativos y que la co-docencia contribuye a la formación pedagógica de los profesores de los dos países. Por otra parte, se observa avances en el aprendizaje de la lengua portuguesa por profesores y estudiantes.

Palabras claves: Educación Superior. Formación del profesorado. Cooperación educativa. 
Raquel Antunes Scartezini

E-mail: raquelscartezini@gmail.com

Manuel Belo de Carvalho

E-mail:mbelodecarvalho@gmail.com
Enviado em: 6/9/2015

Aprovado em: 1/3/2016 